\title{
Magnetoconjugate phenomena in Alaska and Macquarie Is., Australia in 2003: position of the global maximum iso-aurorae
}

\author{
L. A. Hajkowicz \\ Dept. of Physics, University of Queensland, Qld. 4072, Australia
}

Received: 20 December 2005 - Revised: 4 July 2006 - Accepted: 24 August 2006 - Published: 20 October 2006

\begin{abstract}
An extensive magnetometer network in Alaska and Canada (consisting of 6 auroral and sub-auroral stations) and at Macquarie Is. (Australia) was used to study magnetoconjugate phenomena in 2003, using the H-component magnetograms. Altogether 193 magnetically disturbed days (with $\Sigma K_{p} \geq 10$ ) were used in the analysis. The maximum negative swing in the H-component $(\Delta \mathrm{H})$ was assigned for each day from the auroral conjugate station's data. Two types of magnetoconjugate data were found: Type- 1 when the daily (00:00-24:00 h UT) substorm activity was faithfully reproduced in the H-component variations in the northern and southern auroral zones, and Type- 2 when a major peak in disturbance was largely missing in one conjugate location. A distinct maximum in the occurrence of the Type-1 events was in the southern summer (northern winter), reaching almost 70 per cent of cases. A minimum in this type of events was in the southern autumn and winter (around 40\%). The correlation between $\Sigma K_{p}$ and $\Delta \mathrm{H}$ for auroral stations faithfully reproduced the percentage occurrence of the Type1 events for various seasons, with the maximum correlation coefficient $\mathrm{r} \approx 0.8$ in summer.

The time conjugacy of the events (i.e. the events occurring with a small time displacement in the southern and northern auroral zones) was highest for the auroral stations located close to the theoretical conjugate point location at L-value $\approx 5$ (i.e. College and Macquarie Is.). The substorm onsets started earlier at the stations positioned east of the conjugate point of Macquarie Is. in spring and winter, indicating a westward drift of auroral disturbance with velocities of 1.4$1.6 \mathrm{~km} / \mathrm{s}$.

The magnitude of average $\Delta \mathrm{H}$ increased rapidly past the invariant latitude of Macquarie Is. towards the latitude of its nearest northern conjugate station College, particularly in spring. The average level of disturbance was consistently
\end{abstract}

Correspondence to: L. A. Hajkowicz

(lech_hajkowicz@yahoo.co.uk) lower by about 30\% at Macquarie Is. than at College. Since Macquarie Is. is the only available auroral station in the southern auroral zone the maximum southern auroral activity level (maximum iso-aurorae) should be inferred from magnetic data obtained at a northern conjugate station positioned at a slightly higher L-value, such as College ( $\mathrm{L}$-value $=5.73$ ). It is concluded from the above considerations that the maximum iso-aurorae is located at a shell with $\mathrm{L}$-value $\geq 5.73$ in both hemispheres.

Keywords. Magnetospheric physics (Storms and substorms) - Atmospheric composition and structure (Airglow and aurora)

\section{Introduction}

Simultaneous recordings of similar auroral features, at the northern and southern auroral ovals, are associated with charged particles bouncing between mirroring points along a field line. This simple model is distorted during magnetic storms resulting in a shift of the nightside field, i.e. a change occurs in the conjugate point locations. The majority of magnetoconjugate observations in the past were based on simultaneous optical observations of auroras. Recent observations of this type by Stenbaek-Nielsen and Otto (1997) seem to indicate that the conjugacy depends on the type of auroras where the diffuse auroral forms appear to be conjugate whereas discrete auroras are nonconjugate. They explained it by the possibility that the magnetotail is twisted (around the Sun-Earth line) which is linked with the occurrence of a substantial $B_{y}$ component in the interplanetary magnet field (IMF). They also found that this effect can lead to displacement both in longitude and latitude of the conjugate point location. The displacement seems to be most pronounced in longitude, reaching several hundred kilometres, as found from further optical studies by Frank and Sigwarth (2003).

Published by Copernicus GmbH on behalf of the European Geosciences Union. 
Table 1. Geographic and geomagnetic positions of the Alaskan-Canadian magnetic stations and the southern conjugate station Macquarie Is. The local, conjugate and corrected geomagnetic mean midnight (CGM) are indicated for the two principle stations College and Macquarie Is. International Geomagnetic Reference Field (IGRF) model, epoch:1995 (adjusted for the secular variation model for 2003) was used in the field computations at an altitude of $100 \mathrm{~km}$. The negative sign refers to southern latitudes.

\begin{tabular}{|c|c|c|c|c|c|c|c|}
\hline \multirow[b]{2}{*}{ Station } & \multicolumn{4}{|c|}{ Geog.location } & \multicolumn{3}{|c|}{ Mean midnight (UT) } \\
\hline & $\begin{array}{c}\text { Invar. lat } \\
\left({ }^{\circ}\right)\end{array}$ & L-value & $\begin{array}{l}\text { Lat. } \\
\left({ }^{\circ}\right)\end{array}$ & $\begin{array}{l}\text { Long. } \\
\left({ }^{\circ}\right)\end{array}$ & $\begin{array}{l}\text { Local } \\
\text { (h) }\end{array}$ & $\begin{array}{l}\text { Conj. } \\
\text { (h) }\end{array}$ & $\begin{array}{l}\text { CGM } \\
\text { (h) }\end{array}$ \\
\hline Macquarie Is. (M) & -64.33 & 5.41 & -54.5 & 159.0 & 1326 & 1059 & 1153 \\
\hline College (C) & 65.01 & 5.73 & 64.9 & 212.2 & 0954 & 1246 & 1108 \\
\hline Yellow Knife (Y) & 69.32 & 8.15 & 62.4 & 245.6 & & & \\
\hline Gakona $(\mathrm{G})$ & 63.08 & 4.96 & 62.4 & 214.9 & & & \\
\hline Meanook (ME) & 61.97 & 4.60 & 54.6 & 246.7 & & & \\
\hline Anchorage (A) & 60.94 & 4.30 & 61.2 & 210.1 & & & \\
\hline Sitka $(\mathrm{S})$ & 59.77 & 4.01 & 57.1 & 224.7 & & & \\
\hline
\end{tabular}

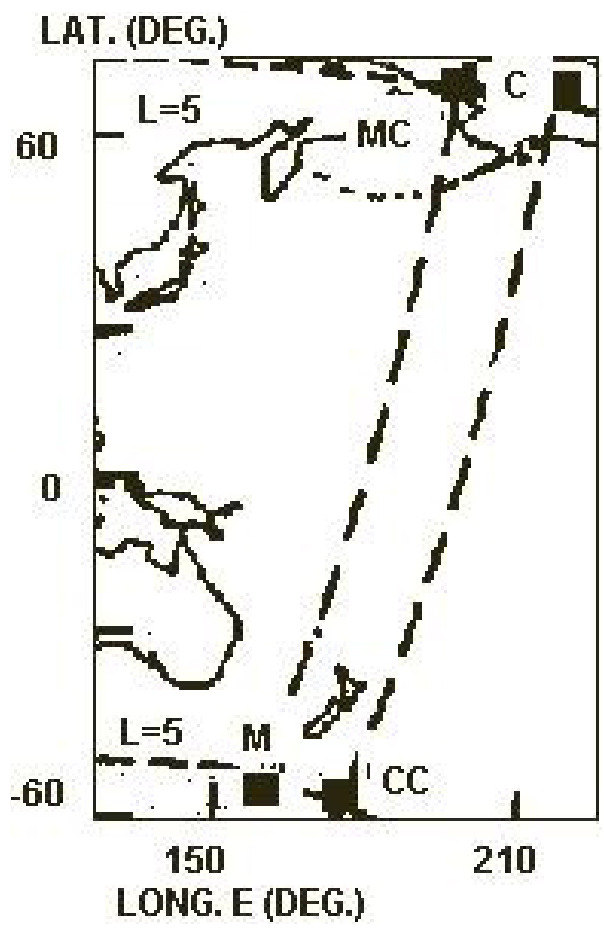

Fig. 1. Locations of the two principle magnetoconjugate stations Macquarie Is. (M) and College (C). The computed conjugate point of Macquarie Is. (MC) is west of College in Alaska (CC refers to the conjugate location of College). The broken lines refer to the magnetic longitudes.

It seems that IMF has a dominant effect on the magnetic field configuration (Burns et al., 1990; Stenbaek-Nielsen and Otto, 1997; Østgaard et al., 2004). It should be stressed that occurrence of an auroral form in one hemisphere only can also arise from differences in ionospheric conductivities in the conjugate locations (Sato et al., 1998).
The first long-term study of the auroral conjugacy at Macquarie Is. (Australia) and Alaska was conducted by Bond (1969). He used all-sky camera data to compare the visual auroral displays at the world's best conjugate pair: Macquarie Is. (Buckles Bay) - Kotzebue, positioned at almost identical invariant latitudes and magnetic longitudes (Macquarie Is.: $64.05^{\circ} \mathrm{S}, 243.64^{\circ} \mathrm{E}$; Kotzebue: $63.98^{\circ} \mathrm{N}$, $242.52^{\circ}$ ). He reported that increases and decreases in the brightness of corresponding auroral forms occurring simultaneously at both stations, to be within $1 \mathrm{~min}$ and were assessed to be of the same intensity. Hajkowicz (1970) used yearly cosmic noise absorption data from vertical incidence riometers situated in Alaska (Kotzebue and College) and at Macquarie Is. It was found, from a statistical study, that the conjugate point to Macquarie Is (during moderate magnetic disturbances, with an average $K_{p}=3$ ) was $170 \pm 60 \mathrm{~km}$ west of Kotzebue. The time conjugacy (i.e. the events occurring at approximately the same time) was much better for KotzebueMacquarie Is. than for College-Macquarie Is. which is associated with College being positioned further east from the conjugate point of Macquarie Is. than Kotzebue. The longitudinal shift between College and Macquarie Is. conjugate, combined with the absorption occurrence time lag, indicated an auroral disturbances drift of about $2 \mathrm{~km} / \mathrm{s}$ both towards east and west. Hajkowicz (1984) analysed 10 years (19711981) of magnetic K-index data for College-Macquarie Is. He reported a strong increase in the local K-index for both stations in a narrow time interval 09:00-12:00 UT, close to the local midnight at College (10:00 UT) when Macquarie Is. was still in the pre-midnight sector. He suggested that the stations are then located in a region which delineates the boundary of the polar cap from which open field lines originate. At this stage, an onset of geomagnetic substorms, due to the particle precipitation from the tail of the magnetosphere, can be recorded. It was further suggested that a difference in the shapes of the northern and southern auro- 
MACQUARIE IS.-ALASKA MAG. STORH 13/05/03

\section{H-component}
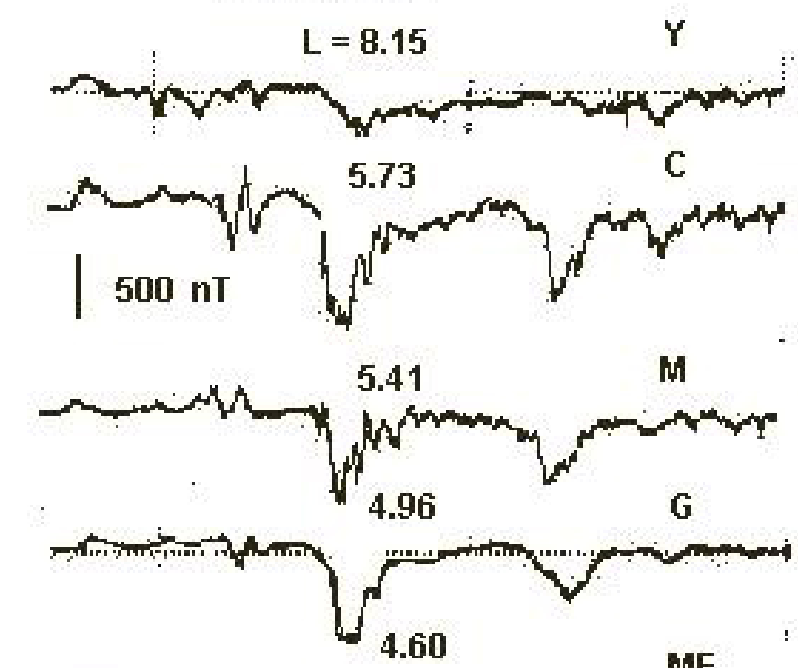

4.60

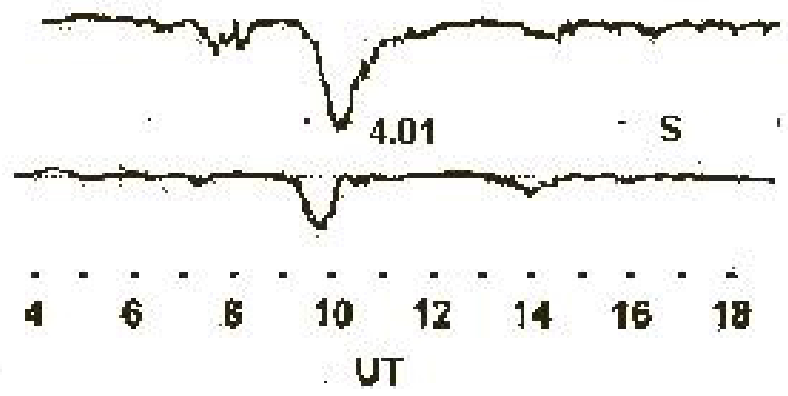

Fig. 2. An example of diurnal (00:00-24:00 UT) substorm activity (Type-1) recorded at a number of the Alaskan and Canadian stations, and Macquarie Is. (symbols of the stations explained in Table 1). The variations in the H-component were faithfully reproduced in the conjugate locations.

ral zones was linked with the selective occurrence time of the substorm onsets. Finally, Hajkowicz (1990) studied the dynamics in the auroral absorption onset in the conjugate regions on a global scale. It was found that the disturbance onset travels mainly westward (with velocities $2.7-4.5 \mathrm{~km} / \mathrm{s}$ ) along the southern and northern auroral ovals (L-value $\approx 5$ ). The absorption levels for the conjugate pair indicated consistently higher magnitude at College than Macquarie Is. A conjugacy breakdown, resulting in an event occurring at one station only, was most common in the southern winter solstice.

It should be noted that all the above results were confined to one southern auroral station, Macquarie Is. Since there is no other typical auroral station in the southern hemisphere (due to the logistics of the terrain) it is important to link the southern auroral data with a number of the northern auroral stations. Such study was conducted, as discussed above, for northern stations displaced in longitude (i.e. Col-
MACQUARIE IS.-ALASKA MAG. STORM:12/02/03

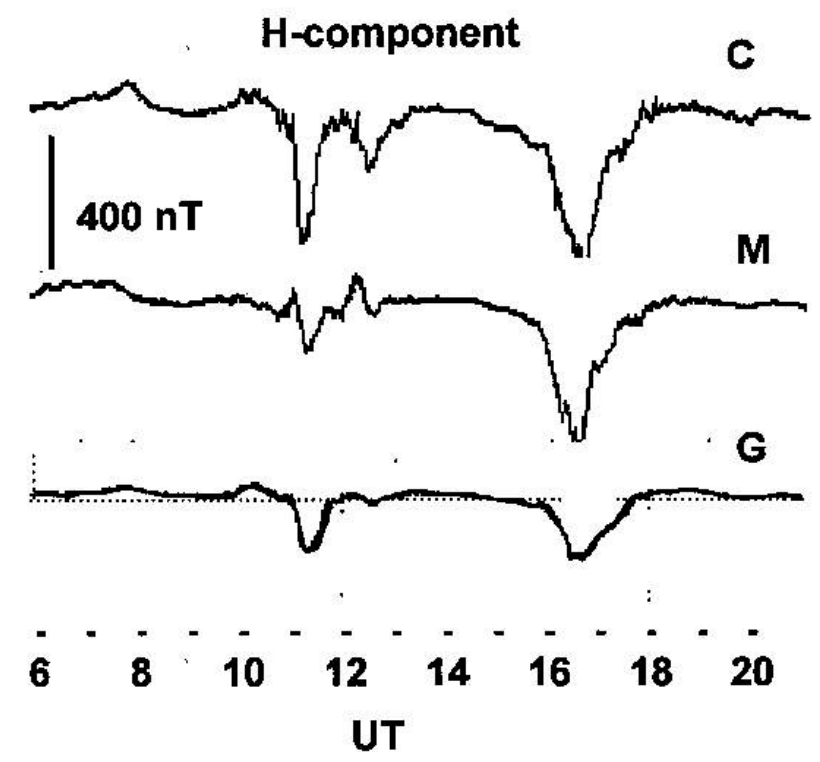

Fig. 3. An example of the Type-2 magnetoconjugate substorm activity. Note the first prominent negative swing in the H-component $(\Delta \mathrm{H})$ at College $(\mathrm{C})$ is largely missing at Macquarie Is. (M).

lege and Kotzebue). Recent establishment of the Alaskan (HAARP) magnetometer chain made it possible to extrapolate the southern latitudinal properties of the conjugate substorm onsets.

\section{Method and results}

A chain of fluxgate magnetometers situated in Alaska, Canada, and Macquarie Is. (Australia), as shown in Table 1, was used to evaluate magnetic H-component disturbance level during 2003. Altogether 193 disturbed days (characterised by $\Sigma K_{p} \geq 10$ ) were used in the analysis.

The geographic positions of the two principle stations used in this study is shown in Fig. 1. Broken lines refer to the geomagnetic longitudes of the stations (as shown in Table 1). It can be seen that the conjugate location of Macquarie Is. (MC) is west of College (C) whose conjugate location is also indicated (CC). The diurnal sectors for $\mathrm{M}$ and $\mathrm{C}$ are largely different both in the local and geomagnetic times (Table 1).

In general, the diurnal substorm activity was similar in the southern and northern locations. Figure 2 shows substorms recorded on 13 May 2003. Note the close similarity in the $\mathrm{H}$-component variations for three stations close to the conjugate positions: Macquarie Is. (M), College (C) and Gakona (G). The amplitude decreased both polewards and equatorwards of these stations. This type of conjugate activity, showing faithful reproduction of the H-component variation in the conjugate locations, was frequent and was classified as Type- 1 of magnetoconjugate phenomena. The classifica- 


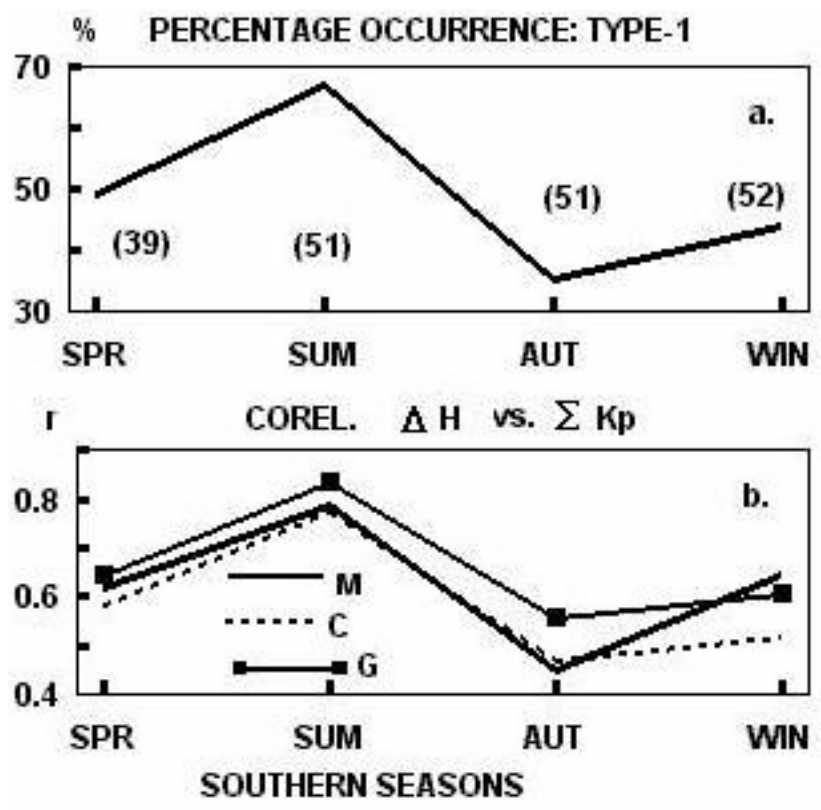

$\Delta \mathrm{H}(\mathrm{nT})$

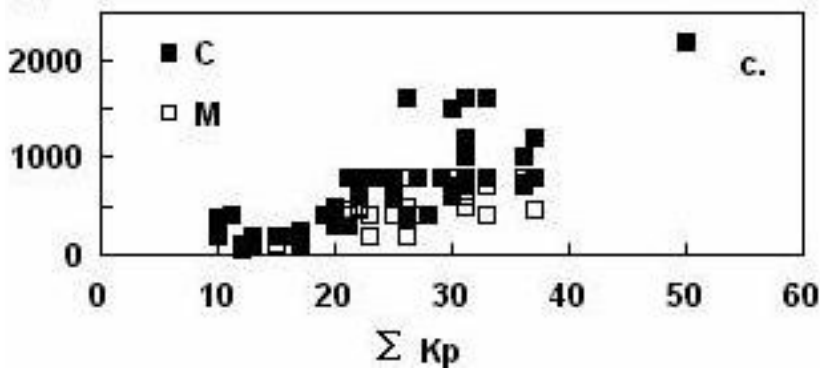

Fig. 4. (a) The seasonal percentage occurrence of the Type- 1 events (the total number of events recorded for each season is indicated in the brackets). (b) The correlation coefficient of $\Delta \mathrm{H}$ with $\Sigma K_{p}$ for three stations. (c) The scatter diagram of $\Delta \mathrm{H}$ vs. $\Sigma K_{p}$ for College and Macquarie Is. for the southern summer.

tion was applied to the diurnal (00:00-24:00 UT) magnetic activity and not to a single event. Less frequent was Type-2 of the global magnetic substorms when conjugacy was imperfect as shown in Fig. 3 (the first peak recorded at College was barely visible at Macquarie Is). Again classification was applied to the diurnal activity when at least one disturbance peak was several times smaller at one station than at the other. In the subsequent analysis the largest negative swing in the $\mathrm{H}$-component magnetogram (herewith referred to as $\Delta \mathrm{H}$ ) was used in the statistical analysis (e.g., the first peak in Fig. 2 and the second one in Fig. 3). Thus, the maximum values were assigned for the conjugate peaks (i.e. for the peaks which were similar in magnitudes in the conjugate locations) and were used in the subsequent analysis. The timing ( $t$ ) of these peaks was used to study the dynamics of conjugate substorm activity.

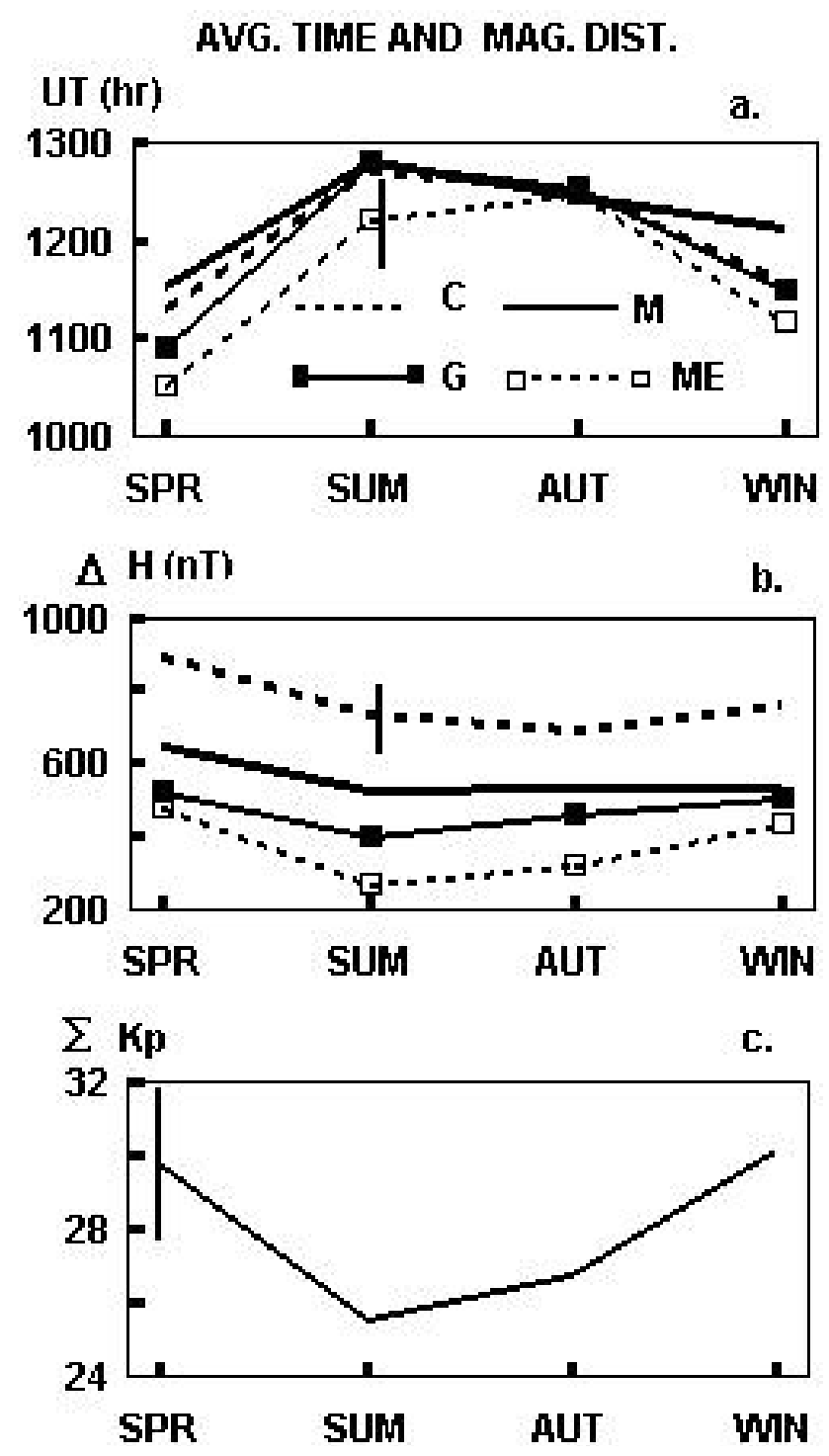

Fig. 5. (a) Average seasonal occurrence time of $\Delta \mathrm{H}$ for four stations. (b) Average seasonal magnitudes of $\Delta \mathrm{H}$ for four stations. (c) Average seasonal $\Sigma K_{p}$ for 2003. Examples of typical standard errors are shown (also indicated in the subsequent diagrams).

The percentage occurrence of Type-1 diurnal magnetic activity is shown in Fig. 4a for the four southern seasons (SPRspring, August-October, SUM-summer, November-January, AUT-autumn, February-April, and WIN-winter, May-July). The total event number is indicated in the brackets for each season. The above season definition will be used herewith unless otherwise indicated. It is evident that the highest degree of magnetic conjugacy (for the two principle stations) was in summer (northern winter). This summer maximum (67\%) sharply contrasted with the occurrence minimum in autumn and winter (35-44\%) whereas spring was characterised by almost equal number of the Type- 1 and Type- 2 periods of magnetic activity. 
LONG. DELAY IN STORM ONSET

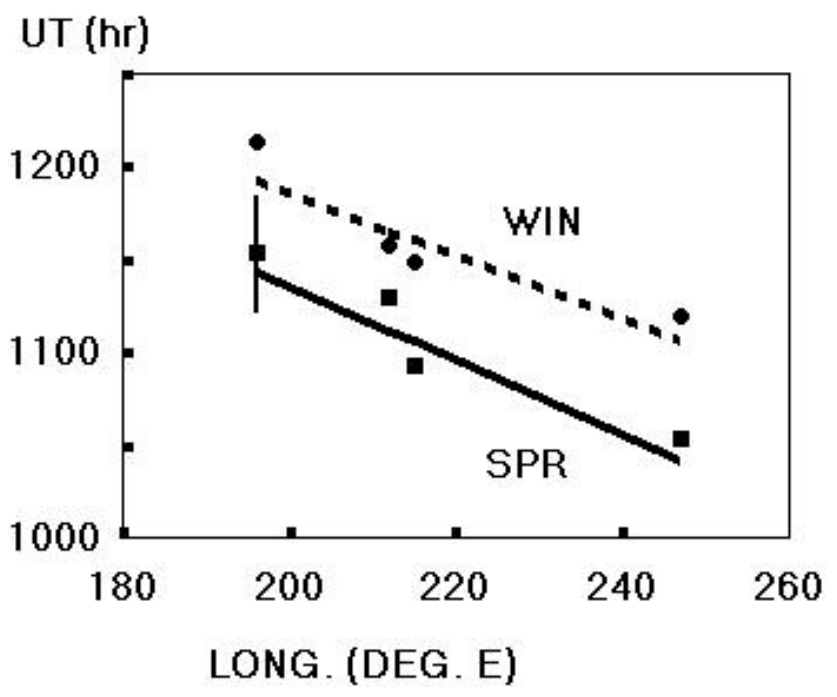

Fig. 6. Linear regression analysis of the time delays at different longitudes for the southern winter (WIN) and spring (SPR).

Figure $4 \mathrm{~b}$ shows the correlation coefficient $\mathrm{r}$ between $\Delta \mathrm{H}$ and the daily planetary index $\Sigma K_{p}$ for closely conjugate stations for all seasons. It can be seen that the different parameters shown in Fig. 4a and b, show the same trend. Thus, the percentage occurrence maximum in the Type-1 magnetic activity in summer is linked with the high correlation between the planetary index $\Sigma K_{p}$ and $\Delta \mathrm{H}$ at the three stations (C, $\mathrm{G}$ and $\mathrm{M}$ ). The correlation coefficient maximum ( $\mathrm{r}=0.83$ for Gakona and slightly less for College- 0.78 , and Macquarie Is.-0.79) in summer coincided with the occurrence maximum for the Type- 1 events. Figure $4 \mathrm{c}$ gives an example of correlation between $\Sigma K_{p}$ and $\Delta \mathrm{H}$ for summer in a scatter diagram form.

Figure 5a shows the average occurrence time $\mathrm{t}$ and $\Delta \mathrm{H}$ for southern seasons. A typical standard error is shown, as an example for summer for ME (similar error indications are given in the subsequent diagrams). There is a diurnal shift in $\mathrm{t}$ for all four stations (M, C, G and ME) from about 11:00 UT (spring and winter) to about 13:00 UT (summer and autumn).

The average $\Delta \mathrm{H}$ for College (Fig. 5b) is consistently higher than that for Macquarie Is. by about $30 \%$. A latitudinal decrease in $\Delta \mathrm{H}$ is observed equatorwards of the latter station. Figure $5 \mathrm{c}$ also shows mean seasonal variations of planetary magnetic activity $\Sigma K_{p}$ in 2003 , with maximum substorm activity in spring and winter and minimum in summer. The summer minimum in substorm activity coincides with the occurrence peak of the Type- 1 events and the highest correlation between $\Delta \mathrm{H}$ and $\Sigma K_{p}$ (Fig. 4).

It can be seen also from Fig. 5a that the average disturbance occurrence time $(\mathrm{t})$ in spring and winter follows a longitudinal sequence from east to west. The easternmost station ME is ahead of $\mathrm{G}$ and then $\mathrm{C}$ and $\mathrm{M}$. This is more clearly

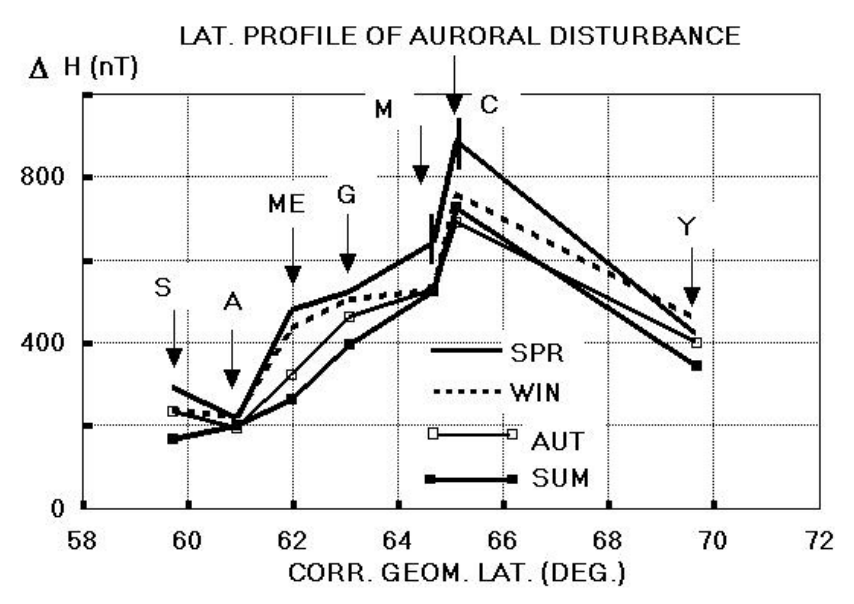

Fig. 7. Invariant latitudinal profiles of average $\Delta \mathrm{H}$ for four seasons. The positions of all the auroral stations are indicated.

evident in Fig. 6 where $t$ is plotted against the longitude of the stations for spring and winter. The linear regression analysis yields the time displacements $\Delta \mathrm{t}$ (between M-ME) of 47 mins and $41 \mathrm{~min}$ for spring and winter, respectively (correlation coeff. $r=0.9$ ). Taking into account the longitudinal separation of ME and M conjugate the westward drift velocities can be computed as $1.4 \mathrm{~km} / \mathrm{s}$ (spring) and $1.6 \mathrm{~km} / \mathrm{s}$ (winter). This type of delay (especially for ME) was also present in summer but not in autumn (Fig. 5a).

The summary of seasonal variations in $\Delta \mathrm{H}$ vs. invariant latititude is shown in Fig. 7 (the positions of the stations are indicated by the arrows). It can be seen that the peak in substorm activity is present at College. The rise in the level of the magnetic disturbance, polewards of Macquarie Is. (e.g. between M-C), is particularly rapid in spring. Here, a change in invariant latitude of $0.77^{\circ}$ (from Table 1) is associated with an H-component enhancement of $245 \mathrm{nT}$ or polewards rise of $318 \mathrm{nT} / \mathrm{deg}$ (or $765 \mathrm{nT}$ per one $\mathrm{L}$-value).

The rapid increase in $\Delta \mathrm{H}$ between $\mathrm{M}$ and $\mathrm{C}$, as compared to the slower increases at lower latitudes, indicates that the magnetic data from these stations can be used to extrapolate the position of the global maximum auroral activity as situated in both hemispheres at $\mathrm{L}$-value $=5.73$ or slightly higher $\left(\mathrm{CGM} \geq 65.1^{\circ}\right)$.

\section{Conclusions and discussion}

The yearly analysis of the H-component magnetic data from seven auroral stations (six in the north and one in the south), positioned in the southern and northern magnetoconjugate areas yielded the following results:

(a) There is a high degree of conjugacy, on the diurnal basis (00:00-24:00 UT), in the onset of geomagnetic substorms, particularly at the stations close to the theoretical conjugate point locations. The substorm events, which were faithfully reproduced at three near-conjugate stations 
College, Gakona (northern auroral zone) and Macquarie Is. (southern auroral zone), were classified as Type-1 as opposed to Type- 2 which showed imperfect conjugacy, with at least one peak in the negative swing of the H-component magnetograms missing in one conjugate location (i.e. $\mathrm{C}$ or M). Percentage occurrence of Type-1 reached maximum of almost $70 \%$ in the southern summer, during relatively quiet geomagnetic conditions. Simultaneously correlation of $\Delta \mathrm{H}$ with $\Sigma K_{p}$ was also highest in summer, with the correlation coefficient close to 0.8 .

(b) There was a sharp rise in the amplitude of magnetic substorms (over $300 \mathrm{nT} / \mathrm{invar}$.deg), from Macquarie Is. to College in a narrow latitudinal region of less than $1^{\circ}$ reaching a maximum in spring.

(c) Since the northern auroral stations and the Macquarie Is. conjugate point were displaced in longitudes it was possible to compute the longitudinal drift of auroral magnetic disturbances from the time shift $t$ in their occurrences. The drift was westward primarily in spring $(1.4 \mathrm{~km} / \mathrm{s})$ and winter $(1.6 \mathrm{~km} / \mathrm{s})$ similar to the westward drift velocities reported from conjugate studies elsewhere (c.f. the Introduction). On the whole, the time conjugacy (i.e. events occurring at the same time) is higher for the stations close to the theoretical conjugate point locations.

It is evident that Macquarie Is., which is the only typical auroral station in the southern hemisphere, is positioned on the equatorwards side of the maximum iso-aurorae. The magnetic data, obtained at this station, provides continuous monitoring of auroral substorm activity in the southern region. An important result of this investigation is that there is a sharp increase in the magnitude of magnetic disturbances polewards of Macquarie Is. and the true level of the disturbance is closer to that indicated by the College magnetogram. Thus, magnetic readings from the southern auroral station underestimate the level of magnetic substorm activity by at least $30 \%$. The same magnitude of difference in auroral activity for these stations was found from a yearly conjugate cosmic noise absorption study by Hajkowicz (1990). He reported that the average absorption onset rate and magnitude decreased rapidly by $25 \%$ between College and Macquarie Is.

The long-time auroral studies at the world's best conjugate pair Kotzebue-Macquarie Is. by Bond (1969) and Hajkowicz (1970), as described in the Introduction, indicate that on the whole levels of auroral disturbances are similar at both locations. Thus, increase in the disturbance level between Macquarie Is. and College is primarily due to an increase in the L-value.

The conjugacy breakdown characterised by the occurrence of Type-2 event was earlier reported by Hajkowicz (1970). He found the presence of the "single ended" auroral absorption peaks (from a conjugate riometer study), suggesting that it is due to a difference of the auroral ovals in the southern and northern hemispheres. It is known that the northern auroral zone is more extended and less circular than the south- ern one as reported from a global study of the auroral occurrences by Khorosheva (1967). This asymmetric shapes may lead to a condition that one station might be outside the auroral oval and thus not accessible to auroral particle precipitation, leading to the conjugacy breakdown (cf. also the Introduction). The asymmetric shapes of the southern and northern auroral oval was further discussed in more detail by Hajkowicz (1984). He found that the onset of auroral substorms at both conjugate locations had a sharp peak at 09:0012:00 UT. This was linked with simultaneous presence of the conjugate station College-Macquarie Is. within the particle precipitation belts in both hemispheres. Due to a large difference in the local midnights for these station, combined with a difference in the shape of ovals, probability of both stations being within the corresponding ovals is more likely during extended nighttime conditions in the north, i.e. during the northern winter and southern summer. It follows that this effect could lead to a better conjugacy in these seasons as observed in the present study.

The results of the statistical studies indicate that, on the whole, the theoretical model used in the computation of the conjugate location is correct. Some departures, however, from the theoretical model, were observed by Østgaard et al., 2004).

in individual cases from optical observation of conjugate auroras in the northern and southern auroral zones. They suggested that the relative displacement in the conjugate hemispheres is associated with the southward interplanetary magnetic field (IMF) penetrating the magnetosphere. They defined conjugacy "as a phenomenon that occurs on the same magnetic field line, connecting two hemispheres, even though the foot points of the field line might have different geomagnetic coordinates".

Further study is required to ascertain the effect of the IMF on the occurrence of Type- 2 events. In addition a study should be undertaken on large differences in the solar illumination conditions in both hemispheres. Specifically, in the southern winter the northern conjugate region is in continuos daylight which results in hemispheric differences in ionospheric conductivity, contributing to the conjugacy breakdown. This may be responsible for an occurrence maximum in non-conjugate events as found from a yearly conjugate study for the same region by Hajkowicz (1990). It should be noted that the close conjugate conjugate pair Macquarie Is.-Kotzebue (c.f. the Introduction) is no longer available and therefore the above effects have to be studied for the stations (College-Macquarie Is.) whose L-values and geomagnetic latitudes are different (Table 1).

Acknowledgements. I am grateful for the global magnetic data made available by HAARP (high frequency active auroral research program, with the magnetic data supplied by the University of Alaska) and Intermagnet (a non-exclusive program of world wide data exchange between magnetic observatories). I am grateful to $\mathrm{K}$. Lynch for his suggestions regarding this report. 
Topical Editor I. A. Daglis thanks M. Fillingim and another referee for their help in evaluating this paper.

\section{References}

Bond, F. R.: Auroral morphological similarities at two magnetically conjugate stations: Buckles Bay and Kotzebue, Aust. J. Phys., 22, 421-433, 1969.

Burns, G. B., McEwen, D. J., Ether, R. A., Berkey, F. T., and Murphree, J. S.: Optical auroral conjugacy: Viking UV imager-South Pole station ground data, J. Geophys. Res., 95, 5781-5790, 1990.

Frank, L. A. and Sigwarth, J. B.: Simultaneous images of the northern and southern auroras from the Polar spacecraft: An auroral substorm, J. Geophys. Res., 108(A4), 8015, doi:10.1029/2002JA009356, 2003.

Hajkowicz, L. A.: Conjugate riometer studies of auroral zone cosmic noise absorption, Aust. J. Phys., 23, 187-196, 1970.
Hajkowicz, L. A.: The onset time interval of geomagnetic disturbances in the conjugate areas, Planet. Space Sci., 32, 819-823, 1984.

Hajkowicz, L. A.: The dynamics of a steep onset in the conjugate auroral riometer absorption, Planet. Space Sci., 38, 127-134, 1990.

Khorosheva, O. V.: Spatial-Temporal distribution of Auroras, Auroras No. 16, Academy of Sciences of the USSR, 1967.

Østgaard, N., Mende, S. B., Frey, H. U., Immel, T. J., Frank, L. A., Sigwarth, J. B., and Stubbs, T. J.: Interplanetary magnetic field control of the location of substorm onset and auroral features in the conjugate hemispheres, J. Geophys. Res., 109, A07204, doi:10.1029/2003JA010370, 2004.

Sato, N., Nagaoka, T., Hashimoto, K., and Saemundsson, T.: Conjugacy of isolated auroral arcs and nonconjugate auroral breakups, J. Geophys. Res., 103, 11 641-11 652, 1998.

Stenbaek-Nielsen, H. C. and Otto, A.: Conjugate auroras and the interplanetary magnetic field, J. Geophys. Res., 102, 2223-2232, 1997. 